\title{
The Geophysical Database Management System in Taiwan
}

\author{
Tzay-Chyn Shin, Chien-Hsin Chang, Hsin-Chieh Pu *, Hsiao-Wei Lin, and Peih-Lin Leu \\ Central Weather Bureau, Taipei, Taiwan
}

Received 22 May 2012, accepted 20 September 2012

\begin{abstract}
The Geophysical Database Management System (GDMS) is an integrated and web-based open data service which has been developed by the Central Weather Bureau (CWB), Taiwan, ROC since 2005. This service went online on August 1, 2008. The GDMS provides six types of geophysical data acquired from the Short-period Seismographic System, Broadband Seismographic System, Free-field Strong-motion Station, Strong-motion Building Array, Global Positioning System, and Groundwater Observation System. When utilizing the GDMS website, users can download seismic event data and continuous geophysical data. At present, many researchers have accessed this public platform to obtain geophysical data. Clearly, the establishment of GDMS is a significant improvement in data sorting for interested researchers.
\end{abstract}

Key words: Geophysical Database Management System (GDMS), Central Weather Bureau (CWB)

Citation: Shin, T. C., C. H. Chang, H. C.Pu, H. W. Lin, and P. L. Leu, 2013: The Geophysical Database Management System in Taiwan. Terr. Atmos. Ocean. Sci., 24, 11-18, doi: 10.3319/TAO.2012.09.20.01(T)

\section{INTRODUCTION}

Seismic monitoring is fundamental for geophysical studies in Taiwan. In fact, monitoring has been in operation since 1897. The first instrument installed in Taipei, the capital of Taiwan, was the Gray-Milne seismograph. Thereafter, nineteen seismic stations were built with this type of mechanical seismograph in Taiwan. From that time to 1973, there were about 3000 felt and damaging earthquakes reported on the basis of this historic network. In 1973, the Taiwan Telemetered Seismographic Network (TTSN) was established by the Institute of Earth Sciences, Academia Sinica (Wang 1989). This network consisted of 25 short period seismic stations distributed widely in Taiwan. Compared with its predecessor, the TTSN could monitor and transmit ground motion data far more efficiently. Between 1973 and 1989, about 90,000 seismic events were recorded by the TTSN. After 1989, these 'second generation' seismic stations were integrated into a new network, the Central Weather Bureau Seismic Network (CWBSN). The CWBSN was established for regional seismic monitoring demanding a dense seismic network with the ability to record and retain real-time digital records. As might be imagined, some tem-

\footnotetext{
* Corresponding author

E-mail:pu@scman.cwb.gov.tw
}

porary and new seismic stations were incorporated within the CWBSN as well. Concurrently, the seismic instruments of each station were also upgraded with the same instrument (the S-13 seismic sensor). This network is the most important seismic network for regional seismic observation in Taiwan.

Over the past 20 years, the CWB also established several types of geophysical stations in the Taiwan area to monitor intense seismicity (e.g., Tsai 1977; Chen et al. 2011) and investigated numerous active faults (e.g., Lin et al. 2000; Shin and Teng 2001; Lin 2004) (Fig. 1). These active regional seismicity and complex structures are caused by two subduction systems, the Eurasian and Philippine Sea plate, in the Taiwan area (Tsai et al. 1977; Angelier 1986). In northeastern Taiwan, the Philippine Sea plate subducts benearth the Eurasian plate. Conversely, the Eurasian plate subducts beneath the Philippine Sea plate in southern Taiwan. Clearly, convergence stress always plays a role to trigger the tectonic activities around the complicated subsurface structures (e.g., Lu and Malavieille 1994; Chang et al. 2003). Currently, the CWB has deployed nearly 1000 seismic stations to monitor regional seismicity and collect seismic data since 1990s. In addition, 150 continuous Global Positioning System (GPS) stations also have been implemented by the CWB to detect crustal deformation since 1994 (Shin et 

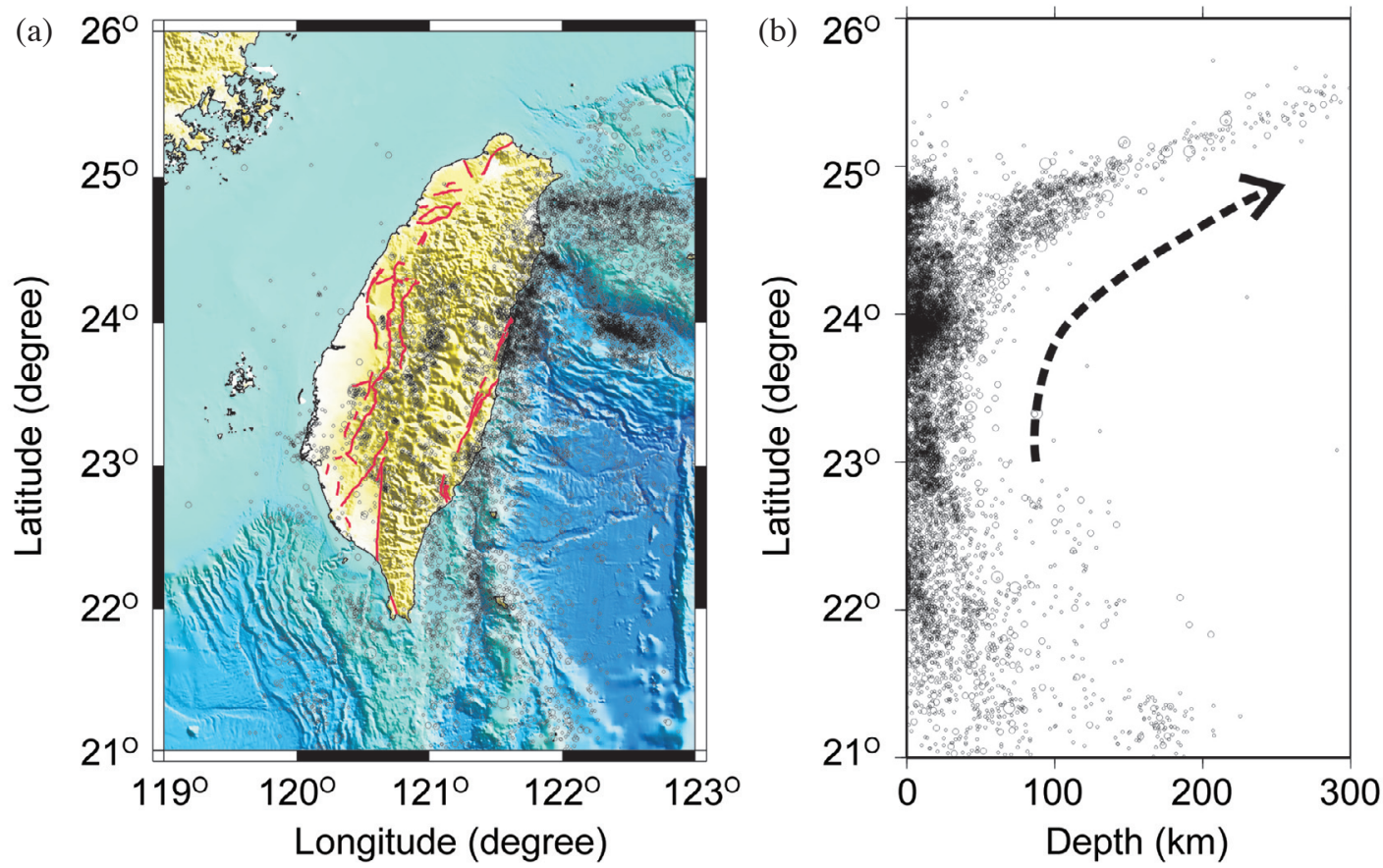

(c)

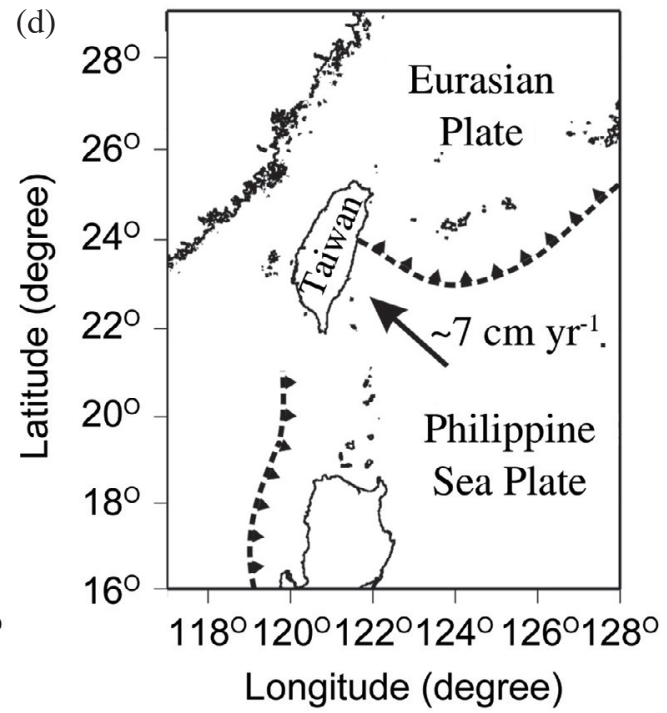

Fig. 1. Seismic and tectonic background in the Taiwan area. (a) The epicenters (open circles; $\mathrm{M}_{\mathrm{L}} \geq 4$ ) and active faults (red solid lines; Lin et al. 2000) in the Taiwan area. (b) Seismic longitudinal projection. The dotted arrow indicates the subduction direction of the Philippine Sea plate. (c) Seismic latitudinal projection. The dotted line indicates the subduction direction of the Eurasian plate. (d) The generalized tectonic background. The dotted lines show the plate boundaries in the Taiwan area. The solid arrow displays the subduction direction in the horizontal attitude, whose velocity is about $7 \mathrm{~cm} \mathrm{yr}^{-1}$ (Yu et al. 1997).

al. 2011). Moreover, groundwater stations were deployed in 2004 as well. In other words, researchers are able to access various types of geophysical data which are collected and managed by the CWB.

To provide observed data conveniently for geophysical research, the CWB attempted to integrate the six geophysical data sets into a platform, the Geophysical Database Management System (GDMS). Geophysical data of the GDMS is collected from the Short-period Seismo- graphic System, Broadband Seismographic System, Freefield Strong-motion station, Strong-motion Building Array, Global Positioning System, and Groundwater Observation System. These geophysical data sets have been collected for some time. In order to construct a friendly service platform, a web-based database system was established over a threeyear testing period with remarkable success. On August 1, 2008, these geophysical data sets can be accessed on the GDMS for users through Internet. 


\section{GEOPHYSICAL DATABASES}

\subsection{Short-Period Seismographic System}

The short-period Seismographic System equipped with high sensitivity sensors is a powerful tool to monitor weak earthquakes. This type of seismic network is deployed widely throughout the world. The Northern California Seismic Network maintained by the US Geological Survey (Oppenheimer et al. 1993) and the high sensitivity seismograph network constructed and operated by the National Research Institute for Earth Science and Disaster Prevention (NIED) in Japan (Hi-net) (Obara 2003) are examples. In Taiwan, this Short-period Seismographic System integrated three former seismic networks from different organizations into a real-time seismic monitoring network in 1989 (Fig. 2a). Originally, the CWB installed fifty new seismic stations for this system. Thereafter, some TTSN stations and eight seismic stations deployed by the National Chung Cheng University were merged within this system. This new integrated seismic network (75 stations) was named the CWBSN since then. Each seismic station in the CWBSN is equipped with S-13 sensors and continuous digital recorder. To provide real-time seismic information, these stations enable the function of real-time data transmission and are deployed evenly covering the entire area of Taiwan (Fig. 2a). As a result, the CWB can detect regional seismicity $\left(M_{L}>2\right)$ in the Taiwan area by taking advantage of this CWBSN. During its operating period in $1989 \sim 2011$, over 400000 events were recorded by this system. Obviously, its detection ability has been significantly improved compared with the predecessors. Also, the continuous seismic waveform has also been archived since December 2003. Before this time, only
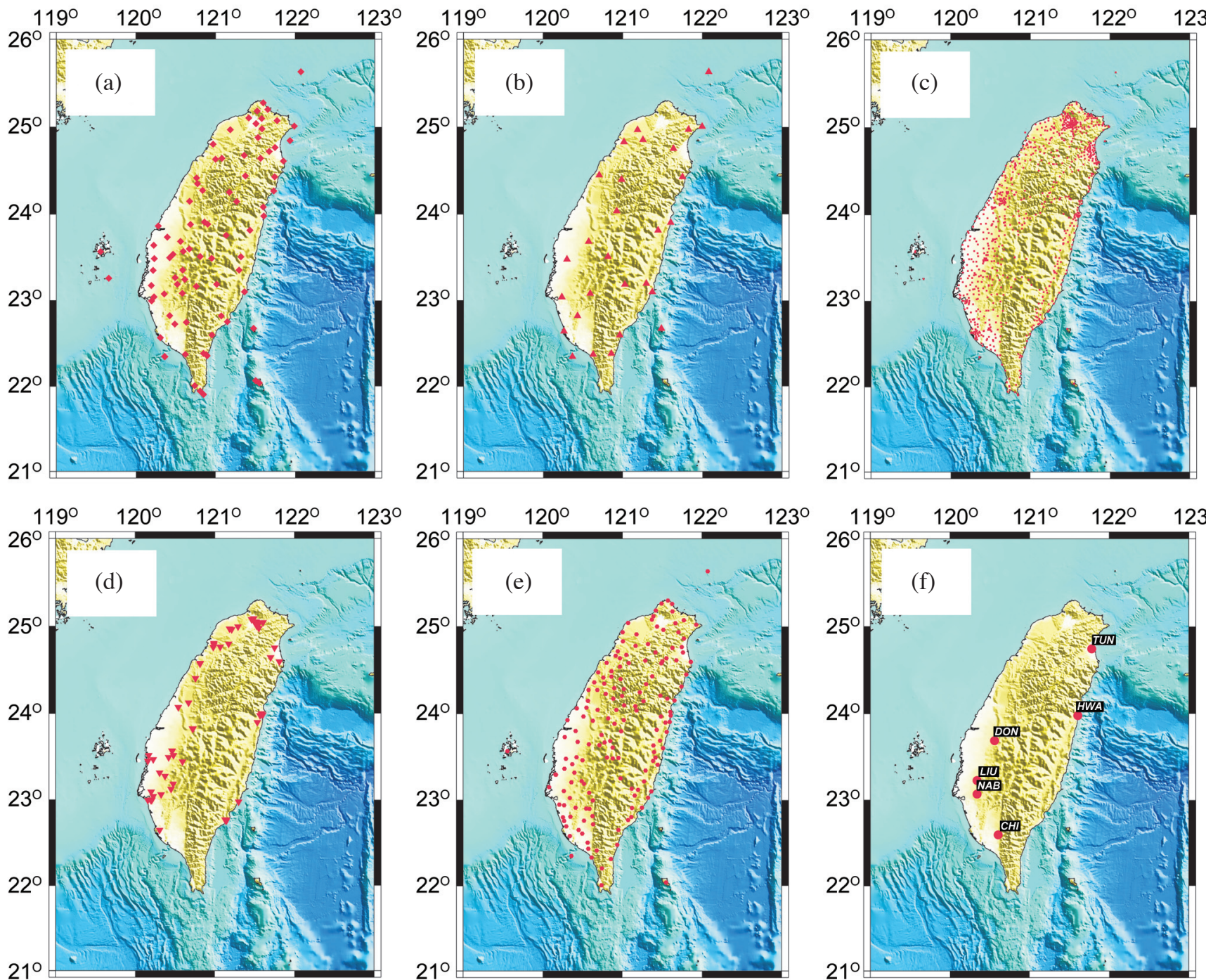

Fig. 2. The geophysical monitoring network in CWB. (a) The Short-period Seismographic System. (b) The Broadband Seismographic System. (c) The Free-field Strong-motion Seismographic System. (d) The Strong-motion Building Array. (e) The Global Positioning System. (f) The Groundwater Observation System. 
triggered event waveform would be stored. In terms of data transmission, field ground motions were transmitted to the CWB data center in Taipei via the T1 cabling in a real-time manner. Therefore, regional seismicity can be determined rapidly and precisely.

\subsection{Broadband Seismographic System}

A broadband seismic network is crucial to seismological research because of its ability to recording signals with wide frequency bands. By inverting the broadband seismic records, the source parameters (e.g., Kao and Jian 1999; Kao et al. 2001) and the source rupture process (e.g., Lee et al. 2008, 2010; Huang et al. 2011) can be determined. In addition, broadband data also provides a constraint for wave propagation simulation on validating models (e.g., Lee et al. 2007). The difference between calculated and observed data can be used to evaluate the seismic site effect.

Based on the above reasons, the CWB started to set up the Broadband Seismographic System monitoring in 2001. At present, the CWB operates 30 broadband seismic stations in the Taiwan area (Fig. 2b). These stations are equipped with Guralp broadband seismometers, Kinemetrics EpiSensor accelerometers and high digital resolution (24-bit) recorders. The long period corners for the broadband sensors can reach to 60 or 120 seconds. Meanwhile, the sampling rate is set at 100 samples per second. Since 2001, more than 21000 events were recorded by this network. Among these events, about 1100 centroid moment tensor solutions were obtained by inverting the seismic broadband waveform.

\subsection{Free-Field Strong-Motion Stations}

In Taiwan, since 1991 there are over 700 strong-motion stations operating under the auspices of an instrumentation project named the Taiwan Strong Motion Instrument Program (TSMIP) (Fig. 2c). These stations are equipped with accelerometers (A800, A900, A900A, IDS3602, IDS3602A, K2, ETNA, CV-574C, CV-575C, and SMART24A) with a full scale of $\pm 2 \mathrm{~g}$ and a dynamic range of 96 or $118 \mathrm{~dB}$. Obviously, the system of free-field strong-motion stations are assigned to record more complete waveforms of hazard earthquakes than the above mentioned systems in this article in the near source area. To save the memory space of recorders in the field, most of these stations are set in a triggering mode with a triggering threshold of $0.003 \sim 0.004 \mathrm{~g}$. However, to record complete earthquake signals, the earthquake waveform would be retained 110 seconds since 20 seconds before the triggering timing. In addition, the sampling rate is set at 200 or 250 samples per second. In the past two decades, this system has collected about 100000 sets of three-component data from 25000 events. These free-field strong-motion records also are used successfully for inves- tigating the seismic site response (e.g., Wen and Peng 1998; Sokolov et al. 2004; Wen et al. 2008).

\subsection{Strong-Motion Building Array}

The Strong-Motion Building Array is used to assess the damage of buildings after a damaging earthquake. The motion of a building is a complex issue because of its direct association with the surrounding outer excitation of the premises as a result of the earthquake, the coupling of the building to the ground, and the mechanical properties of the building (Snieder and Şafak 2006). Thus, it is difficult to calculate the damage of the buildings after the excitation of damaging earthquakes by theoretical modeling. For this reason, the observation of any strong-motion in the building is important. Therefore, the strong-motion building array was designed to record abundant strong motions in a building during potential damaging earthquakes. Then the dynamic response of the buildings, which is strongly related to the damage of the buildings (Rojahn and Mork 1982; Çelebi et al. 1993; Çelebi 2004; Hans et al. 2005; Michel et al. 2010), could be calculated by using these observed data.

To provide vibrant building response data for scientific and engineering communities, the CWB installed 69 strongmotion arrays in buildings beginning in 1992 (Fig. 2d). Generally, each site has at least 20 accelerometers from which a detailed spatial variations building shacking can be easily obtained. The sampling rate of the recorders is set at 200 samples per second because this array is assigned to record the details of a shaking building. By the end of 2011, about 3200 events and 11000 sets of array records were recorded in this array. Furthermore, these building arrays also connected to the warning device with the strong-motion sensor. In other words, this system also provides on-site warning once the shaking becomes significant in buildings.

\subsection{Global Positioning System}

Generally, crustal deformation data are used for tectonic and seismic research in Taiwan. Previously, crustal deformation data have been used to monitor plate motion velocity (Yu et al. 1997). During the 1999 Chi-Chi earthquake, the largest earthquake beneath the Taiwan Island in the $20^{\text {th }}$ century, the GPS data also provide the information of crustal deformation to investigate the fault slip behavior (e.g., Johnson et al. 2001; Yu et al. 2001; Hsu et al. 2007). After the Chi-Chi earthquake, the GPS data are commonly used for some hazard earthquakes in Taiwan (e.g., Chen et al. 2009; Hsu et al. 2009). Moreover, some recent research suggests that this data may also play as an indicator of earthquake precursors (e.g., Roeloffs 2006).

The CWB started operating permanent and continuous GPS stations in 1993 (Fig. 2e). Before the 1999 Chi-Chi earthquake, only 16 continuous GPS stations were installed 
by the CWB. After the 1999 Chi-Chi earthquake, the number of continuous GPS stations was increased gradually. Thus far, about 150 continuous GPS stations have been installed on the island of Taiwan and its surrounding islets (Shin et al. 2011). These GPS stations are equipped with modern receivers (Leica RS500 or TRIMBLE 5700) and antennas (LEIAT 504 or TRM41249). These newly developed instruments record continuous and high resolution (2 samples per 1 minute) data. Although there are many other continuous GPS networks maintained by different organizations, the CWB system has a plurality of monitoring stations.

\subsection{Groundwater Observation System}

The groundwater observation system in Taiwan is to collect the ground water level in the aquifer. This observed information is considered to be a probable indicator of an earthquake precursor in certain cases. Four days before the 1985 Kettleman Hills, California, Earthquake $\left(\mathrm{M}_{\mathrm{w}}=6.1\right)$, the groundwater data appeared to be clearly anomalous (Roeloffs et al. 1997). This anomaly was found in two wells, which are located close to the epicenter. A similar precursor anomaly was also found to be associated with the 1999 Chi-Chi, Taiwan, Earthquake ( $M_{w}$ 7.6) (Chen et al. 2011). For this reason, the CWB instituted a continuous monitoring system for groundwater level started in 2004 (Fig. 2f). This system is composed of six well stations installed in southwestern (DON, LIU, NAB, and CHI) and eastern (TUN and HWA) Taiwan. The wall depths are about $100 \sim 200 \mathrm{~m}$ to match the aquifer in situ. Equipped with state of the art instruments, the groundwater stations were designed for the assessment of possible earthquake precursors. Therefore, this system provides a high sampling rate $(1 \mathrm{~Hz})$ which is continuous and real-time data that make it different from other research wells in the Taiwan area.

\section{CONTRIBUTIONS OF THE GDMS}

To simplify the data request for research, the GDMS was developed by the CWB as a web-based data service platform (http://gdms.cwb.gov.tw/indexphp). This web platform is composed of six servers. These servers are assigned for data storage, sorting, searching, displaying, and backup, separately. The storage capacity is now over $50 \mathrm{~TB}$ which is archived by a disk array with 160 hard disks. The MySQL open source relational database is used for online data sorting. Convenient interfaces on the Apache Web Server were designed to help the data searching and displaying. To secure the archived data in the GDMS, one of six servers was assigned to backup data automatically.

In the GDMS, numerous geophysical data were archived in both continuous and event-based forms. By the end of 2011, the total available data archived in the GDMS was about $21 \mathrm{~TB}$ (Fig. 3). Continuous data recorded by the
Short-period Seismographic System, Broadband Seismographic System, Global Positioning System, and Groundwater Observation System used most of the storage up to 18 TB (Fig. 4a). On the other hand, the event-based data with total size of $3 \mathrm{~TB}$ are also prepared in the GDMS for users (Fig. 4b).

The GDMS has a significant contribution for the users. The main reasons are that the abundant multiple data is prepared in the web-based data service and free of charge for the members of GDMS. In general, the GDMS membership is provided for seismological researchers who are Taiwanese because the charge of data and services is paid by special project expenses funded by the National Science Council, Taiwan. This characteristic has a great help for Taiwanese researchers who unable to acquire the multiple geophysical data alone. As a result, the members are expanding gradually as well as the demand for the geophysical data (Fig. 5). Currently, the total number of GDMS members is about 300 . At this writing, there are about 70 research results provided by the members on the basis of GDMS. Following to our statistics, most geophysical researchers in Taiwan have accessed the GDMS web provisionally indicating that the GDMS has performed successfully in Taiwan. Excluding the Taiwanese researchers, other interested users can also acquire the multiple geophysical data of GDMS via an international cooperation with the member of GDMS.

\section{CONCLUSION}

The Central Weather Bureau (CWB) has constructed the Geophysical Data Management System (GDMS) as a web-based data service platform in Taiwan. This platform provides geophysical data which are collected from the following systems: the Short-period Seismographic System, Broadband Seismographic System, Free-field Strong-motion Station, Global Positioning System, and Groundwater

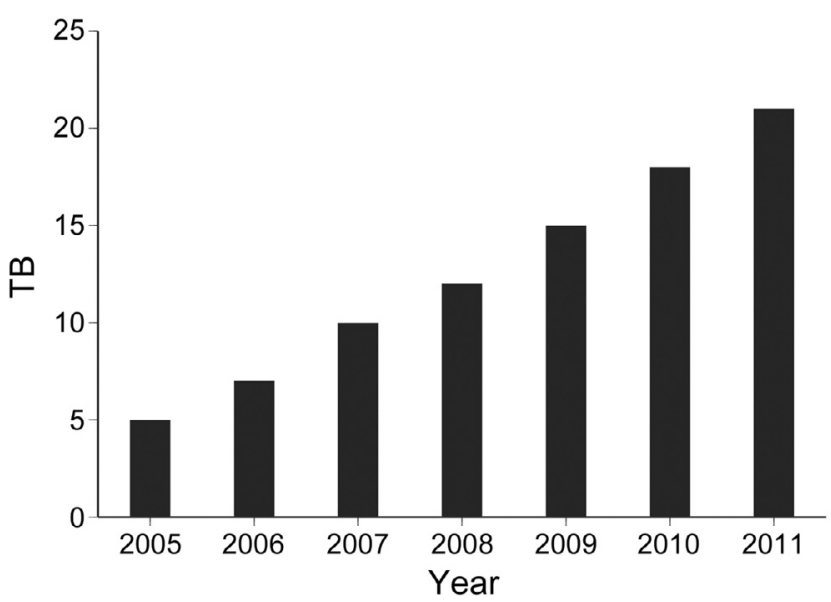

Fig. 3. The cumulated capacity of the database in the GDMS between 2005 and 2011. 
(a)

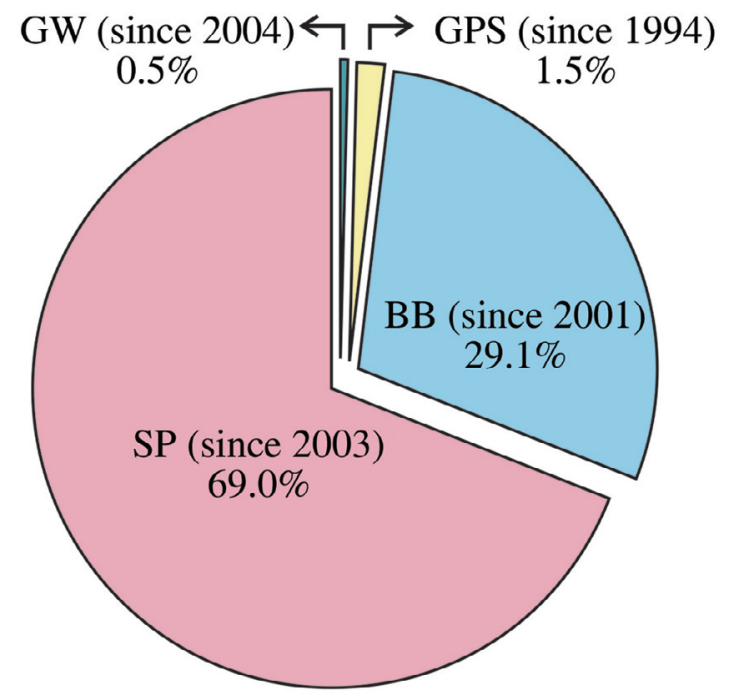

(b)

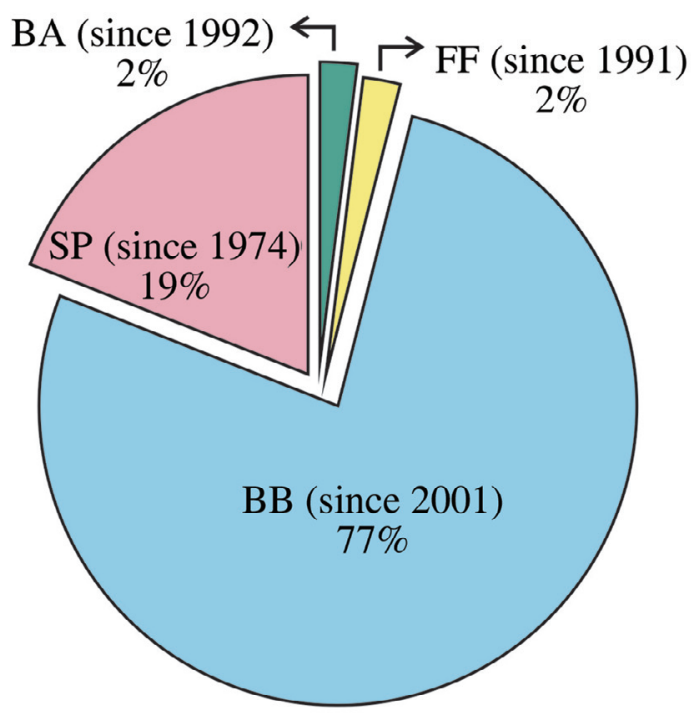

Fig. 4. The pie chart ingredients of the GDMS. (a) is the percentages of the ingredient capacity acquired from the four kinds of continuous monitored records in the GDMS. The total storage capacity is about $18 \mathrm{~T}$ for the continuous data. (b) is the percentages of the ingredient capacity acquired from the four kinds of event-based data in the GDMS. The total storage capacity is about 3T for seismic events. The SP, BB, FF, BA, and GW are simplified from the Short-period Seismographic System, Broadband Seismographic System, Free-field Strong-motion Station, Strong-motion Building Array, and Groundwater Observation System, respectively.

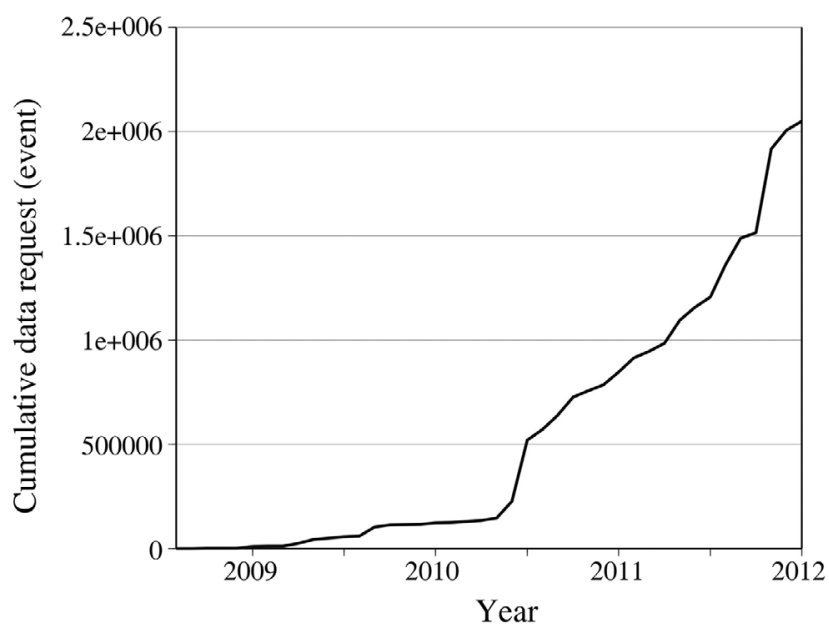

Fig. 5. The cumulative statistics in the request for the geophysical data in GDMS.

Observation System. Users are able to access either continuous or event-based geophysical data from the GDMS in an efficient way. Undoubtedly, the GDMS has successfully promoted geophysical research in Taiwan.

Acknowledgements We thank the useful suggestions from two anonymous reviewers. This research was supported by the Taiwan Earthquake Research Center (TEC) funded through National Science Council (NSC) with grant NSC 99-2116-M052-004, NSC 100-2119-M052-001, NSC 1012116-M052-002. The TEC contribution number for this article is 00087 .

\section{REFERENCES}

Angelier, J., 1986: Preface to the special issue on "Geodynamics of the Eurasial3-Philippine Sea Plate Boundary." Tectonophysics, 125, IX-X, doi: 10.1016/0040-19 51(86)90003-X. [Link]

Çelebi, M., L. T. Phan, and R. D. Marshall , 1993: Dynamic characteristics of five tall buildings during strong and low-amplitude motions. Struct. Des. Tall. Build., 2, 1-15, doi: 10.1002/tal.4320020102. [Link]

Çelebi, M., 2004: Structural monitoring arrays - Past, present and future. In: Gülkan, P. and J. G. Anderson (Eds.), Directions in Strong Motion Instrumentation, 157-179, Springer, Netherlands.

Chang, C. P., T. Y. Chang, J. Angelier, H. Kao, J. C. Lee, and S. B. Yu, 2003: Strain and stress field in Taiwan oblique convergent system: Constraints from GPS observation and tectonic data. Earth Planet. Sci. Lett., 214, 115-127, doi: 10.1016/S0012-821X(03)00360-1. [Link]

Chen, C. H., S. Wen, T. K. Yeh, and C. H. Wang, 2011: Groundwater-deformation coupling in the seismogenic processes of the 1999 Chi-Chi earthquake $\left(M_{w}\right.$ 7.6), Taiwan. AGU Fall Meeting 2011, San Francisco, USA, abstract \#NH23A-1538.

Chen, H. Y , Y. J. Hsu, J. C. Lee, S. B. Yu, L. C. Kuo, Y. L. Jiang, C. C. Liu, and C. S. Tsai, 2009: Coseismic displacements and slip Distribution from GPS and leveling observations for the 2006 Peinan Earthquake $\left(\mathrm{M}_{\mathrm{w}}\right.$ 6.1) in southeastern Taiwan. Earth Planets Space, 
61, 299-318.

Chen, K.H., T. Furumura, J. Rubinstein, and R. J. Rau, 2011: Observations of changes in waveform character induced by the $1999 \mathrm{M}_{\mathrm{w}}$ 7.6 Chi-Chi earthquake. Geophys. Res. Lett., 38, L23302, doi: 10.1029/2011GL049841. [Link]

Hans, S., C. Boutin, E. Ibraim, and P. Roussillon, 2005: In Situ experiments and seismic analysis of existing buildings. Part I: Experimental investigations. Earthq. Eng. Struct. Dyn., 34, 1513-1529, doi: 10.1002/eqe. 502. [Link]

Hsu, Y. J., P. Segall, S. B. Yu, L. C. Kuo, and C. A. Williams, 2007: Temporal and spatial variations of postseismic deformation following the 1999 Chi-Chi, Taiwan earthquake. Geophys. J. Int., 169, 367-379, doi: 10.1111/j.1365-246X.2006.03310.x. [Link]

Hsu, Y. J., S. B. Yu, and H. Y. Chen, 2009: Coseismic and postseismic deformation associated with the 2003 Chengkung, Taiwan, earthquake. Geophys. J. Int. 176, 420-430, doi: 10.1111/j.1365-246X.2008.04009.x. [Link]

Huang, B. S., Y. L. Huang, P. L. Leu, and S. J. Lee, 2011: Estimation of the rupture velocity and fault length of the 2004 Sumatra - Andaman earthquake using a dense broadband seismic array in Taiwan. J.Asian Earth Sci., 40, 762-769, doi: 10.1016/j.jseaes.2010.10.020. [Link]

Johnson, K. M., Y. J. Hsu, P. Segall, and S. B. Yu, 2001: Fault geometry and slip distribution of the 1999 ChiChi, Taiwan earthquake imaged from inversion of GPS data. Geophys. Res. Lett., 28, 2285-2288, doi: 10.10 29/2000GL012761. [Link]

Kao, H. and P. R. Jian, 1999: Source parameters of regional earthquakes in Taiwan: July 1995-December 1996. Terr. Atmos. Ocean. Sci., 10, 585-604.

Kao, H., Y. H. Liu, and P. R. Jian, 2001: Source parameters of regional earthquakes in Taiwan: January-December, 1997. Terr. Atmos. Ocean. Sci., 12, 431-439.

Lee, S. J., H. W. Chen, and K. F. Ma, 2007: Strong ground motion simulation of the 1999 Chi-Chi, Taiwan earthquake from a realistic three-dimensional source and crustal structure. J. Geophys. Res., 112, B06307, doi: 10.1029/2006JB004615. [Link]

Lee, S. J., W. T. Liang, and B. S. Huang, 2008: Source mechanisms and rupture processes of the 26 December 2006 Pingtung earthquake doublet as determined from the regional seismic records. Terr. Atmos. Ocean. Sci., 19, 555-565. doi: 10.3319/TAO.2008.19.6.555(PT). [Link]

Lee, S. J., B. S. Huang, W. T. Liang, and K. C. Chen, 2010: Grid-based moment tensor inversion technique by using 3-D Green's functions database: A demonstration of the 23 October 2004 Taipei Earthquake. Terr. Atmos. Ocean. Sci., 21, 503-514, doi: 10.3319/TAO.20 10.01.25.02(TH). [Link]

Lin, C.H., 2004: Repeated foreshock sequences in the thrust faulting environment of eastern Taiwan. Geophys. Res. Lett., 31, L13601, doi: 10.1029/2004GL019833. [Link]

Lin, C. W., H. C. Chang, S. T. Lu, T. S. Shih, and W. J. Huang, 2000: An Introduction to the Active Faults of Taiwan: Explanatory Text for the Active Fault Map of Taiwan, Scale 1:500000. Second Edition, Special Publication of Central Geological Survey, MOEA, Taiwan, $13,122 \mathrm{pp}$.

Lu, C. J. and J. Malavieille, 1994: Oblique convergence, indentation and rotation tectonics in the Taiwan mountain belt: Insights from experimental modelling. Earth Planet. Sci. Lett., 121, 477-494, doi: 10.1016/0012-8 21X(94)90085-X. [Link]

Michel, C., P. Guéguen, S. E. Arem, J. Mazars, and P. Kotronis, 2010: Full-scale dynamic response of an RC building under weak seismic motions using earthquake recordings, ambient vibrations and modelling. Earthq. Eng. Struct. Dyn., 39, 419-441, doi: 10.1002/eqe.948. [Link]

Obara, K., 2003: Hi?net: High sensitivity seismograph network, Japan. In: Takanami, T. and G. Kitagawa (Eds.), Methods and Applications of Signal Processing in Seismic Network Operations, Lecture Notes Earth Sciences, 98, 79-88, Springer, Berlin.

Oppenheimer, D., F. Klein, J. Eaton, and F. Lester, 1993: The Northern California Seismic Network Bulletin January - December 1992. USGS Open-File Report 93 578.

Roeloffs, E., 2006: Evidence for aseismic deformation rate changes prior to earthquakes. Annu. Rev. Earth Planet. Sci., 34, 591-627, doi: 10.1146/annurev .earth.34.0314 05.124947. [Link]

Roeloffs, E., E. Quilty, and C. H. Scholtz, 1997: Case 21: Water level and strain changes preceding and following the August 4, 1985 Kettleman Hills, California, earthquake. Pure Appl. Geophys., 149, 21-60 doi: 10.1007/ BF00945160. [Link]

Rojahn, C. and P. N. Mork, 1982: An analysis of strong motion data from a severly damaged structure - The Imperial county services building, El Centro, California. In: The Imperial Valley, California, Earthquake of October 15, 1979, Geological Survery Professional Paper 1254, United States Government Printing Office, Washington.

Shin, T. C. and T. L. Teng, 2001: An overview of the 1999 Chi-Chi, Taiwan, earthquake. Bull. Seismol. Soc. Am., 91, 895-913, doi: 10.1785/0120000738. [Link]

Shin, T. C., K. W. Kuo, P. L. Leu, C. H. Tsai, and J. S. Jiang, 2011: Continuous CWB GPS array in Taiwan and applications to monitoring seismic activity. Terr. Atmos. Ocean. Sci., 22, 521-533, doi: 10.3319/TAO.20 11.05.18.01(T). [Link]

Snieder, R. and E. Şafak, 2006: Extracting the building re- 
sponse using seismic interferometry: Theory and application to the Millikan Library in Pasadena, California. Bull. Seismol. Soc. Am., 96, 586-598, doi: 10.17 85/0120050109. [Link]

Sokolov, V., A. Ovcharenko, C. H. Loh, and K. L. Wen, 2004: Seismic hazard assessment for the Taiwan region on the basis of recent strong-motion data and prognostic zonation of future earthquakes. Nat. Hazards, 33, 319-363, doi: 10.1023/B:NHAZ.0000048464.45565.b0. [Link]

Tsai, Y. B., T. L. Teng, J. M. Chiu, and H. K. Liu, 1977: Tectonic implications of the seismicity in the Taiwan region. Mem. Geol. Soc. China, 2, 13-41.

Wang, J. H., 1989: The Taiwan Telemetered Seismographic Network. Phys. Earth Planet. Inter., 58, 9-18, doi: 10.1016/0031-9201(89)90090-3. [Link]

Wen, K. L. and H. Y. Peng, 1998: Site effect analysis in the
Taipei basin: Results from TSMIP network data. Terr. Atmos. Ocean. Sci., 9, 691-704.

Wen, K. L., C. M. Lin, H. J. Chiang, C. H. Kuo, Y. C. Huang, and H. C. Pu, 2008: Effect of surface geology on ground motions: The case of station TAP056 - Chutzuhu site. Terr. Atmos. Ocean. Sci., 19, 451-462, doi: 10.3319/TAO.2008.19.5.451(T). [Link]

Yu, S. B., H. Y. Chen, and L. C. Kuo, 1997: Velocity field of GPS stations in the Taiwan area. Tectonophysics, 274, 41-59, doi: 10.1016/S0040-1951(96)00297-1. [Link]

Yu, S. B ., L. C. Kuo, Y. J. Hsu, H. H. Su, C. C. Liu, C. S. Hou, J. F. Lee, T. C. Lai, C. C. Liu, C. L. Liu, T. F. Tseng, C. S. Tsai, and T. C. Shin, 2001: Preseismic deformation and coseismic displacements associated with the 1999 Chi-Chi, Taiwan earthquake. Bull. Seismol. Soc. Am., 91, 995-1012, doi: 10.1785/0120000722. [Link] 